\title{
A produção artística de Tom Zé na década de I970: considerações sobre o projeto da música "operária" e o disco Estudando o samba
}

\author{
[ The artistic production of Tom Zé in the I970s: considerations on the \\ project of "worker" music and the disc "Estudando o samba"
}

\section{Guilherme Araujo Freire ${ }^{\mathrm{I}}$}

Este texto é parte de capítulo da dissertação de mestrado Vanguarda, experimentalismo e mercado na trajetória artística de Tom Zé, apresentada ao Programa de Pós-Graduação em Música do Instituto de Artes da Universidade Estadual de Campinas em 2015.

\begin{abstract}
RESUMO-Este artigo trata da produção artística do compositor Tom Zé realizada durante o seu período de ostracismo e procura compreender melhor as especificidades de sua atuação e inserção no mercado musical brasileiro. Com base em discursos presentes em matérias publicadas em periódicos, pesquisamos o sentido da ação do compositor baiano ao desenvolver um projeto que designou como "música operária": uma pesquisa experimental com ferramentas, máquinas de oficina e sons oriundos da execução de fitas magnéticas. Considerando que, na década de I970, o gênero samba passava por uma fase de revitalização e ascensão de popularidade no mercado, realizamos um estudo sobre o disco Estudando o samba (I976), verificando de que maneira Tom Zé se posicionou artisticamente nos debates estéticos sobre o gênero. • PALAVRAS-CHAVE • Música popular; canção;
\end{abstract}

experimentalismo. A ABSTRACT . This article deals with the artistic production of the composer Tom Zé performed during his period of ostracism and seek to better understand the specifics of his actuation and insertion in the Brazilian musical market. Based on discourses present in articles published in journals, we researched the meaning of action of the composer Tom Zé in developing the project of "worker music", accomplishing an experimental research with tools, workshop machinery and sounds derived from the playing of magnetic tapes. Considering that, in the I970s, the genre samba was going through a phase of revitalization and popularity in the market, we conducted a study on the album "Estudando o samba" (I976), verifying how Tom Zé positioned himself artistically in the ongoing aesthetic debates about the genre. KEYWORDS .Popular music; song; experimentalism.

Recebido em 7 de março de $20 I 7$

Aprovado em I8 de outubro de 2017

FREIRE, Guilherme Araujo. A produção artística de Tom Zé na década de I970: considerações sobre o projeto da música "operária" e o disco Estudando o samba. Revista do Instituto de Estudos Brasileiros, Brasil, n. 68, p. I22-I44, dez. 2017.

DOI: http://dx.doi.org/Io.II606/issn.23I6-90IX.voi68pI22-I44

I Universidade Estadual de Campinas (Unicamp, Campinas, SP, Brasil). 
Quando se analisa em perspectiva a produção de Tom Zé realizada ao longo de sua carreira artística, torna-se notável o caráter contestador de suas composições. A postura contrária aos referenciais hegemônicos da canção da MPB e aos padrões de "bons costumes" da sociedade se manifesta não apenas no plano musical, no qual o artista praticou experimentalismos e buscou uma linguagem inovadora desde o seu primeiro LP, mas também nos diversos aspectos artísticos de sua atividade, como performances, entrevistas, temáticas críticas dos seus discos, letras, arranjos, capas, sonoridade das músicas, entre outros. No entanto, dado que sua atuação acontece no campo da música popular, com regras determinadas, padrões de linguagem consolidados, hierarquia artística estabelecida e mecanismos de atuação da indústria crescentemente racionalizados, torna-se complexa e conflituosa sua relação com o mercado.

No início de sua carreira, Tom Zé encontrou espaço para o seu projeto estético transgressor junto ao tropicalismo, participando na gravação do LP-manifesto do movimento Panis et circensis (I968), ao lado de seus companheiros baianos Caetano Veloso, Gilberto Gil, Gal Costa, Capinan, entre outros. Atuou assim ativamente no movimento de renovação da música popular brasileira (MPB) associado ao incorporar símbolos da modernidade (guitarras elétricas, órgão, procedimentos da música de vanguarda erudita) com fins de romper com certas concepções puristas de tradição, cultivadas por alguns segmentos de esquerda no período. Através de composições que teciam críticas à ideologia moralista e ao otimismo desenvolvimentista do regime militar, como "Parque industrial" e "São São Paulo", conquistou prêmios no IV Festival de MPB (I968) da TV Record e considerável destaque na mídia do período.

Entretanto, nos anos seguintes após o término do tropicalismo, Tom Zé passou a ter maiores dificuldades em sua carreira artística, uma vez que se tornavam cada vez mais limitados os espaços para novos artistas e novas sonoridades no mercado. Considerando que a indústria fonográfica contava com uma hierarquia artística já consolidada no início dos anos 1970 - o que permitia que as grandes gravadoras pudessem prover a realização dos lucros através de casts estáveis que vendiam uma quantidade considerável de discos -, perdia-se a partir daí a preocupação com a 
busca de novas tendências e novos talentos ${ }^{2}$. Assim, foi justamente nesse contexto desfavorável para inovações musicais e experimentalismos que Tom Zé radicalizou os seus experimentos musicais e poéticos, desconstruindo em suas composições a poética eloquente e emocional da canção tradicional da MPB e adaptando procedimentos musicais da vanguarda da música erudita ao campo de música popular.

Apesar das dificuldades de atuação, Tom Zé conseguiu ainda assim lançar seis LPs durante as décadas de I970 e I980. Contudo, sua carreira permaneceu em baixa até ser descoberto pelo produtor escocês David Byrne em fins da década de I980 e ter uma coletânea de músicas lançada no mercado exterior com considerável repercussão internacional. Após o lançamento do disco Com defeito de fabricação (I998), conquista uma fervorosa aclamação de público e crítica, consagrando-se no mercado internacional e encerrando os longos anos de ostracismo no Brasil. Anos após o seu "esquecimento" no espólio do tropicalismo, Tom Zé adquiriu status e tornou-se em relativamente pouco tempo um símbolo da criatividade artística, da singularidade da música brasileira e da produção de vanguarda da música popular ${ }^{3}$ no exterior, amplamente festejado por uma estética e por procedimentos musicais, os quais ele já esboçava em seus discos anteriores.

Neste artigo estabelecemos como foco central a atividade e produção artística de Tom Zé realizada durante o início do seu período de ostracismo, situado entre os anos de 1973 e I979, procurando compreender melhor as especificidades de sua inserção no mercado, bem como investigar as mudanças no seu projeto estético. Procuramos também problematizar as relações entre as opções estéticas de Tom Zé, sua forma de atuação no mercado do período e o segmento conhecido como cultura marginal - identificando afinidades, diferenças e mediações estabelecidas entre as duas partes. Com base em discursos presentes em matérias publicadas em periódicos, investigamos ainda o sentido da ação de Tom Zé ao desenvolver uma pesquisa performática experimental de timbres e sonoridades inusitadas com ferramentas, máquinas de oficinas e sons oriundos da execução de fitas magnéticas manipuladas através de equipamentos eletrônicos, bem como as possíveis razões de tais decisões estéticas.

\section{Produção musical e atividade artística de TOM ZÉ DURANTE O OSTRACISMO}

Em uma matéria publicada pela Folha de S. Paulo, em I973, o compositor baiano declarava: "Eu estou escapando da morte. Quando posso pelo movimento. Quando posso pela dentada. Quando posso pelo riso. Com um relativo medo da flor, da dor, que parece uma maneira velha, quer dizer, uma maneira morta de dizer coisas mais

2 PAIANO, Enor. O berimbau e o som universal: lutas culturais e indústria fonográfica nos anos 6o. Dissertação (Mestrado em Comunicação). Escola de Comunicações e Artes, Universidade de São Paulo, I994, p. 2I3-2I7.

3 Não queremos aqui entrar no mérito de a discussão da produção de Tom Zé ser ou não de vanguarda, ou citar autores da teoria da vanguarda, mas apenas indicar ao leitor como o artista passou a ser reconhecido pela crítica especializada e pelos meios midiáticos nacionais e internacionais a partir da década de I990. 
velhas e mais certas"4. De uma maneira poética e não linear o depoimento traz sinais da situação em que se encontrava a atividade de Tom Zé na década de I970: "escapando da morte", com apresentações restritas a um público reduzido, formado em grande parte por universitários.

Após a ousadia criativa e a repercussão desfavorável causada pelo disco Todos os olhos (I973), Tom Zé começou a ter maiores dificuldades de atuação no mercado e passou a realizar apresentações em espaços alternativos de menor visibilidade, como galerias de arte, fundações, teatros e anfiteatros universitários do interior de São Paulo, longe de meios massivos de difusão como a televisão. Passou a fazer também outros tipos de trabalho muitas vezes nem mesmo vinculados à atividade cancionista, como dar aulas de violão, atuar como auxiliar de produção em um documentário da TV Cultura, ou realizar trabalhos temporários como produtor musical. Observemos dois trechos de matérias de jornal que fazem alusão a tais atividades:

Para sobreviver, Tom Zé tem feito shows para estudantes e aceitou recentemente, um emprego de produtor musical na agência de publicidade DPZ. Lá, eventualmente, também fará Jingles. Está também fazendo a versão da ópera Evita de Webber e Tim Rice para o português, sob encomenda de sua editora, a MCA5.

TZ - Sei que nunca vendi muito disco e nem fiz muito sucesso, mas a música tem me dado outros prazeres como esse de conversar e discutir com a classe estudantil. No final de cada apresentação tem alguém me perguntando [...] $]^{6}$.

Apesar das condições adversas de sua carreira e de constituir um investimento de risco para as gravadoras por não garantir um retorno financeiro mínimo, Tom Zé conseguiu ainda assim produzir mais três álbuns durante o seu período de ostracismo. Dois deles pela gravadora Continental - Estudando o samba (I976) e Correio da Estação do Brás (I978) - e o terceiro pela gravadora RGE, intitulado Nave Maria (I984). Mesmo com baixa perspectiva no mercado, Tom Zé continuou investindo convictamente no seu projeto estético experimental, praticando novas formas de composição e criando novos recursos para os arranjos. Contudo, a recepção dos seus discos durante a década de 1980 continuou em baixa, em grande parte devido ao distanciamento do seu projeto estético em relação aos padrões da vertente principal da MPB.

Em um período em que a MPB já havia finalizado seu processo de institucionalização, com uma determinada hierarquia artística e estatuto básico de criação ${ }^{7}$, aqueles que não integraram seu projeto artístico aos cânones estilísticos e musicais consolidados e que empregaram práticas criativas consideradas ousadas e transgressoras frente a determinados padrões estéticos acabaram perdendo seu

4 TOM ZÉ “escapando da morte”. Folha de S. Paulo, Ilustrada, 6 mar. I973, p. 5.

5 SOARES, Dirceu. Tom Zé, do Brás ao Jardim América. Folha de S. Paulo, Ilustrada, 2I mai. I977, p. 2.

6 ARROJO, Maria José. Tom Zé, um quarentão inocente. Folha de S. Paulo, Ilustrada, 3 dez. I977, p. I.

7 NAPOLITANO, Marcos. Seguindo a canção: engajamento político e indústria cultural na MPB (I959-I969). São Paulo: Annablume/Fapesp, 200I. 
espaço na cena artística "oficial" e sendo rotulados como "malditos" ou "marginais". Foi ao longo da década de 1970 que tais rótulos ganharam evidência, fazendo referência tanto às baixas vendagens de discos obtidas por alguns artistas, como também ao teor hermético de suas composições e a certa postura underground, contrária a padrões culturais, estéticos e políticos propagados pelo regime militar. Além de Tom Zé, artistas como Jards Macalé, Jorge Mautner, Walter Franco, Marcus Vinicius, Hareton Salvanini também praticaram procedimentos de cunho experimental, explorando os limites da arte cancionista e abraçando o ideário de uma cultura avessa ao mainstream, cujo estatuto básico era colocar-se à margem dos sistemas político e cultural dominantes.

Pensando nesse tipo de produção, algumas questões tornam-se pertinentes para compreendermos melhor o sentido da ação desses artistas durante o período. Por que investir parte de suas obras e carreiras em pontos, temas e estéticas não reconhecidas ou toleradas pela maior parte da sociedade brasileira? Por que persistir em uma linha estética divergente dos cânones musicais consolidados no mercado? Por que buscar nas imperfeições, no pessimismo, nos exotismos, fraquezas e defeitos as representações de uma proposta estética transformadora da sociedade?

Em Eu, brasileiro, confesso minha culpa e meu pecado, livro que trata da cultura marginal no Brasil desse período, o pesquisador Frederico Coelho destaca que o termo marginal passou a ser corrente a partir de alguns eventos culturais ${ }^{9}$. Segundo o autor, as declarações e trabalhos de Glauber Rocha e de Hélio Oiticica entre I965 e I968, as manifestações tropicalistas na música popular, as publicações do semanário carioca O Pasquim, os filmes de cineastas como Ozualdo Candeias, Rogério Sganzerla, Neville d'Almeida, entre outros, traziam as bases do que ficou designado como cultura marginal.

Para o pesquisador, no momento em que alguns cineastas, artistas plásticos, compositores, músicos, jornalistas e escritores se assumem marginais diante do mercado consumidor e das práticas culturais vigentes, eles criam para sua própria "sobrevivência intelectual" um espaço em que regras, cânones ou respeito às "tradições nacionais" foram abolidos em prol de uma maior liberdade de ação e de opinião. Desse modo, os diversos tipos de produção marginal (cinema, música, imprensa etc.) configuraram-se como os únicos espaços onde um tipo específico de produção e reflexão cultural pôde ser feito ${ }^{\text {Io }}$.

Assim, se pensarmos nessa delimitação de espaços e nas ações desses agentes situadas em um contexto de lutas simbólicas com vistas à legitimação cultural no campo artístico, podemos interpretar essa postura underground como um tipo de estratégia intencional de atuação. Nesse sentido, as práticas que fundamentavam a cultura marginal não devem ser vistas como uma forma de atuação passiva, ou "menor", de artistas naquele momento, mas sim como um posicionamento consciente e ativo. Elas expressavam uma decisão de um grupo ativo de agentes culturais pelo

8 ZAN, José Roberto. Jards Macalé: desafinando coros em tempos sombrios. Revista USP, n. 87, 20Io, p. I64-I65.

9 COELHO, Frederico. Eu, brasileiro, confesso minha culpa e meu pecado: cultura marginal no Brasil das décadas de I960 e I970. Rio de Janeiro: Civilização Brasileira, 20I0, p. 208-2I7.

Io Ibidem, p. 200. 
rompimento com certas bases da produção cultural brasileira que, em algumas áreas, estavam sendo transformadas em lugares-comuns do conservadorismo militarista e de classe média ${ }^{\text {II }}$.

Apesar de seu projeto estético apresentar pontos divergentes dos de outros artistas associados à cultura marginal, Tom Zé parece ter introjetado o mesmo habitus artístico e compartilhado do mesmo tipo de estratégia consciente de atuação no campo. Ao optar por manter suas convicções estéticas, continuar tensionando certos padrões de beleza instituídos no mercado e desenvolver ainda mais seus métodos de experimentação durante um período tão longo (I7 anos), Tom Zé o faz com uma atitude programática, com vistas a um projeto maior de legitimação no campo artístico, o qual seria consumado apenas tardiamente (década de I990).

Após o início da vigência do AI- $5^{\mathrm{I2}}$, o exílio de alguns intelectuais e artistas centrais da música popular brasileira e a censura de obras importantes, o campo artístico da década de 1970 transformou-se em um terreno aberto para a disputa de posições no âmbito da produção cultural. Nesse cenário, a cultura marginal apareceu como produto de um grupo atuante e passou a fazer parte dos debates intelectuais. Ao que tudo indica, esse parece ser o caso de Tom Zé, pois ao longo de sua trajetória artística empreendeu conscientemente uma busca constante pela inovação formal e por soluções criativas, recorrendo muitas vezes a experimentalismos e à irracionalidade, como forma de negação do que estava sendo instituído no plano cultural, de tensionar as imagens de um otimismo desenvolvimentista propagado pelo regime militar.

Nesse período, estar à margem consistia não em uma postura de desistência ou passividade de tais artistas, mas em uma tomada de posição consciente diante das possibilidades de atuação disponíveis. Ao invés de se colocarem a par de certos modelos compatíveis com o gosto popular, o que muitas vezes significava abrir mão da criatividade e da inovação formal em seus trabalhos, alguns artistas preferiram manter suas preferências estéticas e atuar de maneira mais autônoma em relação às tendências do mercado.

Não por acaso, depois de ter lançado o LP Estudando o samba (I976) e de estar há alguns anos já com a carreira artística em baixa, Tom Zé decide desenvolver ainda mais seu projeto estético experimental, iniciando uma pesquisa musical de timbres com ferramentas, máquinas de oficinas e a manipulação da execução de fitas magnéticas com equipamentos eletrônicos. Em um depoimento proferido no "calor do momento", o compositor iraraense esclarece sua concepção musical para a pesquisa:

II Ibidem.

I2 O Ato Institucional no 5 (AI-5), decreto emitido pelo regime militar brasileiro no ano de I968, sobrepunha-se à Constituição de 1967 e concedia poderes extraordinários ao presidente da República. Além de ter posto em recesso várias garantias constitucionais, fechou o Congresso Nacional, suspendeu os direitos políticos e civis aos considerados subversivos, aprimorando assim a instrumentalização da ditadura para o recrudescimento da repressão e da censura. É considerado como o marco do período mais violento da ditadura militar, entre outras razões, por numerosas denúncias de assassinatos e tortura de presos políticos, bem como exílio e desaparecimento de militantes de esquerda. 
Um rapaz sempre irrequieto, Tom Zé faz o espetáculo, com intenção “experimental”, utilizando para isso vários instrumentos de trabalho dos operários: serrote, martelo, esmeril, britadeira. Tom Zé explica: "Enquanto integrador de materiais e sonoridades novas, este projeto pode ter o sentido de experimentalidade, mas não é encaminhado às elites. Desejamos fazer uma música tão operária como fomos nós os próprios marceneiros, os carregadores, os desenhistas, os inventores dos instrumentos”³.

A ideia de produzir uma “música operária”, além de apontar a simpatia de Tom Zé com as teorias marxistas de luta de classes, destaca ainda mais o caráter experimental do seu projeto estético, uma vez que agrega procedimentos experimentais similares aos da música erudita de vanguarda no âmbito da canção popular. Tal iniciativa foi tomada após as experiências que o artista teve ao ajudar o cineasta Walter George Durst na gravação de um programa de natal para a TV Cultura, o qual registrou as festas de fim de ano de nordestinos imigrantes situados no bairro do Brás da cidade de São Paulo ${ }^{\mathrm{I}}$. Ao ter contato com os imigrantes nordestinos, Tom Zé se sensibiliza e pouco tempo depois resolve produzir o LP Correio da Estação do Brás (I978) como uma espécie de retrato dessas pessoas, que muitas vezes levavam cartas aos parentes de outrem quando voltavam às suas terras natais.

I3 TOM ZÉ ligado às origens. O Estado de S. Paulo, Geral, 20 mai. I978, p. I2.

I4 SOARES, Dirceu, I977, op. cit. 


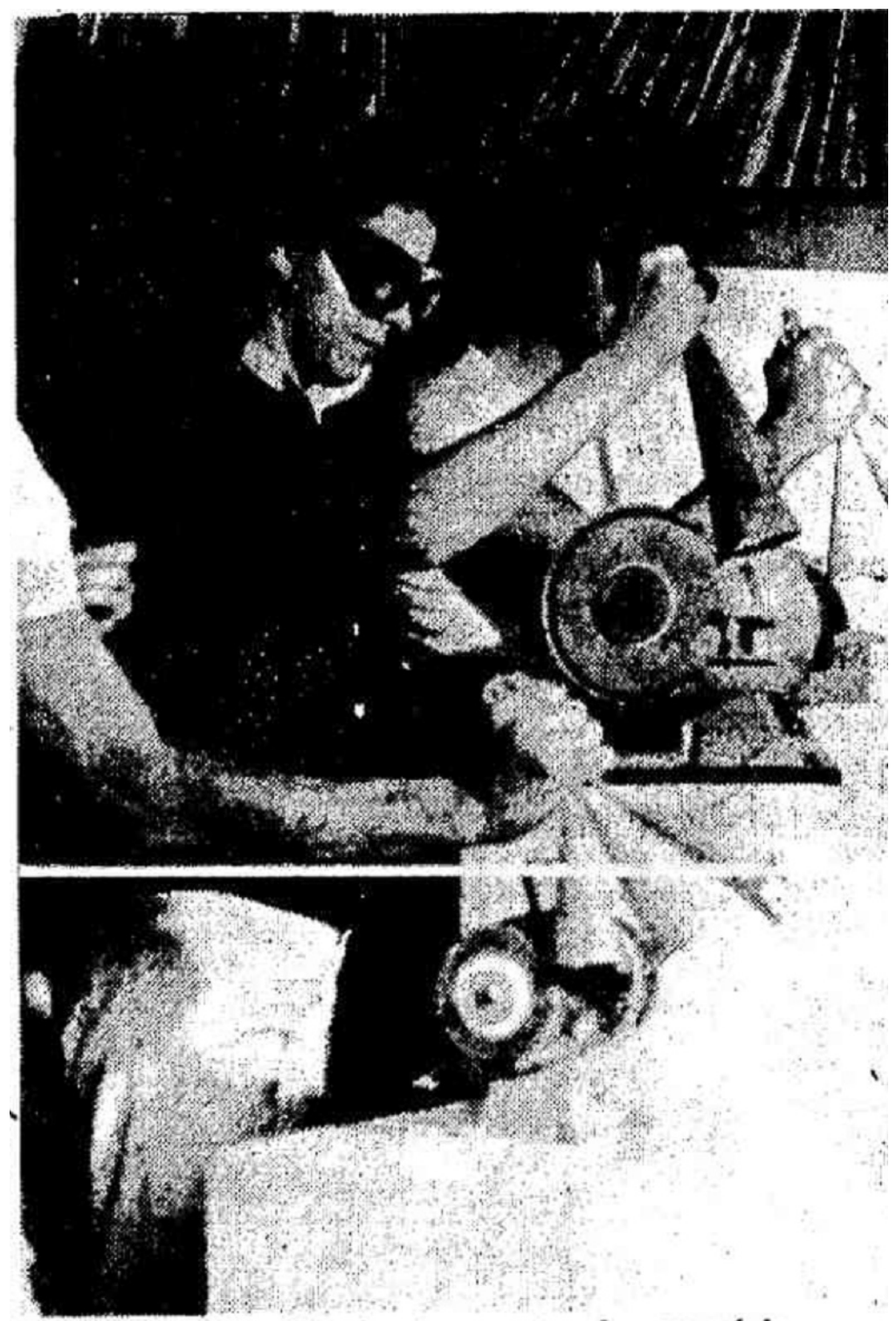

\section{Tom Zé utiliza instrumentos dos operários}

Figura I - Fotografia presente em matéria publicada sobre o lançamento do LP Correio da Estação do Brás. Fonte: O Estado de S. Paulo, Geral, 20 mai. I978, p. I2

A pesquisa experimental combinava diferentes recursos (mecânicos, elétricos, eletrônicos) na busca de timbres e sonoridades inusitados: enceradeiras acopladas a uma caixa acústica, dois agogôs em atrito com um esmeril industrial (Figura I), um pedaço de cano de ferro que ressoa com o ferimento feito nele por dois serrotes, e até mesmo três gravadores com fitas de sons mixados e manipulados por uma mesa de controle (uma espécie de antepassado do sampler), que consistia em uma caixa 
com seis botões, os quais acionavam a reprodução de uma amostra de som - voz de locutores de rádio, frases de propagandas, a obra Halleluja de Haendel, trechos de sinfonias orquestrais, entre outras ${ }^{15}$.

Nosso objetivo, explica Tom Zé, “é encontrar uma sintaxe, uma possibilidade desses sons todos formarem música”. Tom Zé diz que está emocionado com a nova experiência, pois além das perspectivas que ela abre, de criação coletiva, existe também uma nova maneira de "fazer música”

Ao empregar objetos do cotidiano (serrote, martelo, esmeril, cano) como instrumentos de percussão, de maneira a executarem linhas de condução rítmica e formarem a seção rítmica de determinado gênero (por exemplo, samba ou baião), Tom Zé adaptava um procedimento típico dos concretistas franceses para o universo da música popular. Tal procedimento ficou marcado nos anos I950, quando compositores franceses, como Pierre Schaeffer e Pierre Henry, ganharam certa notabilidade ao compor a partir da manipulação de fitas magnéticas, criando montagens com gravações dos sons do cotidiano (como vassouras em fricção com o chão, um trem percorrendo os trilhos, água escorrendo da torneira) modificados e reorganizados sistematicamente ${ }^{\mathrm{I7}}$.

Como uma espécie de Eric Satie do sertão, Tom Zé aplicava seus conhecimentos dos procedimentos artísticos das vanguardas, adquiridos nos seminários de música da Universidade Federal da Bahia (UFBA) através das aulas de professores como H. J. Koellreutter, Ernest Widmer, Jamary Oliveira, em busca de uma nova sintaxe possível de canção - colocando a arte cancionista em confronto com seus limites. Ao que tudo indica, a convivência com o músico e artista plástico suíço Walter Smetak na Bahia possivelmente também contribuiu diretamente nessa decisão estética, uma vez que o fez ter contato com alguns processos criativos referentes à arte contemporânea do período, como, por exemplo, uma pesquisa musical acústica que buscava apropriar-se da matéria e do ambiente, o que levou Smetak a criar instrumentos musicais inovadores feitos com cabaça, bambu, cabo de vassoura, sinos, entre outros materiais ${ }^{18}$. Nesse projeto da "música operária”, Tom Zé parece reproduzir a intenção de apropriação de materiais locais dessa pesquisa acústica, porém readaptada e direcionada à linguagem da música popular.

Apesar de alguns críticos e jornalistas terem demonstrado certa simpatia com as invenções, o novo projeto experimental do compositor baiano acabou sendo mal recebido pelo público e, ao que tudo indica, foi impedido de ser utilizado no LP Correio da Estação do Brás pela gravadora Continental. Pouco tempo depois do

I5 É possível ver um registro audiovisual de uma performance de Tom Zé e seu grupo, com cada um desses instrumentos inventados, no documentário: TOM ZÉ ou Quem irá colocar uma dinamite na cabeça do século? Direção: Carla Gallo. 2000. DVD.

I6 DUCLOS, Nei. Contradições de um artista em construção. Folha de S. Paulo, Ilustrada, I9 mai. I978, p. 2.

I7 GRIFFITHS, Paul. A música moderna: uma história concisa e ilustrada de Debussy a Boulez. Rio de Janeiro: Jorge Zahar, I998, p. 48.

I8 SCARASSATTI, Marco Antônio Farias. Walter Smetak, o alquimista dos sons. São Paulo: Perspectiva, 2008, p. I5. 
lançamento do disco, Tom Zé acabou sendo afastado do cast da gravadora por ter conseguido vender 5 mil cópias, algo que contribuiu para o artista ter recebido o rótulo de "maldito" e para que sua carreira artística continuasse em baixa até o final da década de I980. O projeto da "música operária" terminou ficando sem registro em disco e foi abandonado durante dez anos, muito provavelmente devido à repercussão desfavorável causada e ao alto custo de transporte e manutenção de toda a aparelhagem envolvida.

\section{REVITALIZAÇÃo do SAMBA NA DÉCADA DE I970 E A CONCEPÇÃo ARTÍSTICA DE TOM ZÉ EM ESTUDANDO O SAMBA}

Ao analisarmos os discursos de jornalistas, críticos, músicos e as representações formadas sobre canções ligadas ao gênero samba nos anos I970, nota-se um volume considerável de críticas que compartilhavam certo aspecto crítico comum. Versos como "Depois que o visual virou quesito/ Na concepção desses sambeiros/ O samba perdeu a sua pujança/ Ao curvar-se à circunstância/ Imposta pelo dinheiro/ E o samba que nasceu menino pobre/ Agora se veste de nobre/ No desfile principal/ Onde o mercenarismo impõe a sua gana/ E o sambista que não tem grana/ Não brinca mais o carnaval" da canção "Visual", de Neném e Pintado, expressavam a opinião de grupos de sambistas que se mostravam descontentes com as transformações pelas quais o gênero passava no período, preocupados com a sua descaracterização pelos imperativos mercadológicos.

De certo modo, os versos apresentam indícios da grande repercussão comercial e da popularidade que o gênero obteve na maior parte dos anos I970 no eixo Rio de Janeiro-São Paulo, com os sucessos de vendas de uma nova geração de artistas, como Alcione, Beth Carvalho, Clara Nunes, Jorge Aragão, Nei Lopes, Wilson Moreira, bem como de outros artistas anteriormente já reconhecidos pelo público, como Paulinho da Viola e Martinho da Vila. Tais indícios ganham feições de evidência quando se consultam as estatísticas do Nopem ${ }^{\text {I9 }}$ apresentadas pelo pesquisador Eduardo Vicente, com dados sobre os 50 discos mais vendidos por ano no período, distribuídos em uma tabela por segmentos, como internacional, pop romântico, MPB, rock, samba, trilha sonora, infantil etc. ${ }^{20}$. Observando-se a tabela que consta no artigo, percebe-se que o número de discos do segmento samba apresentou uma redução paulatina entre I968 e I97I. Contudo, a partir de I972, começa a aumentar progressivamente até alcançar o ponto máximo em I976, contando com onze LPs nas paradas de sucessos - período no qual superou os números de discos do segmento de MPB e do segmento romântico,

I9 Nopem constitui uma sigla da empresa Nelson Oliveira Pesquisas de Mercado, cuja atividade se dá em pesquisas na área do mercado fonográfico, incluindo a publicação de uma lista dos 50 discos mais vendidos com periodicidade anual. Essas listas foram produzidas a partir de 1965 e serviram como referência para o trabalho do pesquisador Eduardo Vicente.

20 VICENTE, Eduardo. Segmentação e consumo: a produção fonográfica brasileira - I965/I999. ArtCultura, v. Io, n. I6, 2008, p. 99-II7. p. I07. 
ficando atrás apenas do segmento internacional. Em seguida apresenta um leve decréscimo até o último ano da década, apresentando nove discos na lista.

A popularidade do gênero também foi apontada por publicações de críticos e jornalistas influentes no período, como Tárik de Souza, que chega a designar o samba como o "ritmo da moda" e destacar sua presença "na linha de frente das paradas de sucessos" e também nas "incontáveis casas noturnas paulistas e copiosas rodas de sambas dos clubes e churrascarias cariocas" ${ }^{21}$. Outro jornalista e crítico musical influente do período que corrobora essa ideia, Sérgio Cabral, afirmava em uma entrevista concedida por ele à revista Veja, de I979, que o samba era naquele momento uma moda em expansão, dado que as gafieiras estavam tomando os espaços que eram até então ocupados pelas discotecas. A seguir, na entrevista, Cabral conclui que a ascensão do gênero era "um fenômeno de todos os anos I970, onde o samba entrou -e nunca mais saiu - das paradas de sucessos" ${ }^{2}$. Em outra matéria, intitulada "Samba, artigo de consumo nacional”, de Margarida Autran, publicada pela primeira vez em I979, a autora também destaca a grande popularidade do gênero, iniciando o texto designando os anos I970 como "a década do samba" e destacando que o ano de I975 ficou "definitivamente marcado como o ano do samba para as gravadoras" ${ }^{23}$.

Todavia, enquanto alguns setores viam com bons olhos a revitalização e as transformações pelas quais passava o samba, outros apresentavam uma visão mais crítica, associando à sua ascensão no mercado um processo de padronização de procedimentos musicais, distanciamento da "tradição" e perda das práticas originais realizadas em comunidades. Além dos versos críticos do samba "Visual”, de Neném e Pintado, apontados anteriormente, a análise feita pelo jornalista Tárik de Souza não deixa de estabelecer uma ligação crítica entre a ascensão do gênero nas paradas de sucesso e certo processo de padronização:

Costurada ao instável marketing das gravadoras, a atual ascensão do samba às paradas resultou numa quase fatigante repetição de fórmulas e imagens. E as empresas que não possuíam matrizes capazes de produzir aplausos e cruzeiros decidiram lançar-se à batalha armadas de modestos seguidores e imitadores ${ }^{24}$.

Realizando uma análise orientada por referenciais adornianos, Souza destaca que, por consequência das estratégias de marketing e da concorrência entre gravadoras, o samba estava sendo associado a um esquema de fins comerciais, com a "quase fatigante" repetição de fórmulas de sucesso. A seguir, na matéria, o jornalista cita alguns exemplos de lançamentos de diferentes gravadoras para embasar seu ponto de vista, destacando quais eram os artistas "matrizes", quais eram as suas respectivas cópias, e analisando o panorama do segmento naquele período. Em outro artigo, a

2I SOUZA, Tárik de. País do samba. Veja, n. 37I, I5 de outubro, I975, p. I2I-I22.

22 CABRAL, Sérgio. A subida do samba. Veja, n. 586, I979, p. 3-6. Entrevista concedida a Elizabeth Carvalho.

23 AUTRAN, Margarida. Samba, artigo de consumo nacional. In: NOVAES, Adauto (Org.). Anos 70: ainda sob a tempestade. Rio de Janeiro: Aeroplano/Editora Senac Rio, 2005, p. 7I-78.

24 SOUZA, Tárik de, I975, op. cit., p. I22. 
jornalista Margarida Autran também compartilhou da mesma crítica ao avanço da lógica comercial na dinâmica de produção do gênero:

Mas foi em 197I que alguns acontecimentos aparentemente isolados propiciaram as condições para a deflagração da maciça comercialização que, mais tarde, viria a desvirtuar toda uma cultura popular comunitária [...]. O samba perderia suas características regionais para se transformar em cultura de massa, vendável a todo tipo de público ${ }^{25}$.

Em uma via interpretativa similar à de Souza, porém imbuída de uma crença nostálgica em valores de "autenticidade" e "pureza", Autran atribui à larga comercialização do gênero o distanciamento de suas origens comunitárias, que teria desvirtuado a cultura popular comunitária e o transformado em cultura de massa, apontando, desse modo, um fenômeno de massificação na produção desse segmento. Com uma visão menos idealizada das práticas do samba em suas origens comunitárias, o pesquisador Eduardo Vicente também aponta esse fenômeno, destacando em seu trabalho que possivelmente tenha sido o samba "o grande fenômeno de massificação do mercado musical dos anos $70^{\prime 26}$.

No livro Música popular: de olho na fresta, o sociólogo e jornalista Gilberto Vasconcellos apresenta uma visão crítica similar à dos outros autores citados, acusando redundância em um tipo de samba designado sambão-joia ${ }^{27}$ praticado naquele momento e o criticando pelo mau gosto e padronização de certos procedimentos:

De uns anos pra cá (I970, se se quiser datar), é impossível ouvir samba sem arrepiar os cabelos de tédio. Em termos estéticos, a banalidade campeia à solta: texto pobre repleto de lugares-comuns, sempre à caça do efeito, ou seja, daquela paradinha esperada no meio da canção com a entrada triunfal da cuíca e o exaltado chorinho meloso das vozes femininas ${ }^{28}$.

Como pudemos perceber, diversos jornalistas e críticos tinham uma opinião crítica comum sobre a popularização do samba em suas análises, destacando, nas transformações correntes do gênero, certo processo de padronização, descaracterização de suas práticas originais, perda de originalidade criativa, fenômeno que associaram ao avanço da racionalidade mercadológica e às estratégias de marketing. Alguns músicos, compositores e intérpretes também expressaram

25 AUTRAN, Margarida, op. cit., p. 54 .

26 VICENTE, Eduardo. Música e disco no Brasil: a trajetória da indústria nas décadas de 80 e 90 . Tese (Doutorado em Comunicações). Escola de Comunicações e Artes, Universidade de São Paulo, 200I, p. 76.

27 O tipo de samba conhecido como sambão-joia foi objeto de um estudo extenso realizado pelo pesquisador Adelcio Camilo Machado em sua pesquisa de mestrado. Para mais informações, ver: MACHADO, Adelcio Camilo. Quem te viu, quem te vê: o samba pede passagem para os anos I970. Dissertação (Mestrado em Música). Instituto de Artes, Universidade Estadual de Campinas, 20 II.

28 VASCONCELLOS, Gilberto. Música popular: de olho na fresta. Rio de Janeiro: Edições do Graal, I977, p. 77. 
uma opinião similar em algumas de suas canções, como "Argumento", de Paulinho da Viola ("Tá legal, eu aceito o argumento/ Mas não me altere o samba tanto assim/ Olha que a rapaziada está sentindo a falta/ De um cavaco, de um pandeiro ou de um tamborim"); a canção "Agoniza, mas não morre", de Nelson Sargento (“Samba/ Inocente, pé no chão/ A fidalguia no salão/ te abraçou, te envolveu/ Mudaram toda tua estrutura/ Te impuseram na cultura/ E você não percebeu").

Compartilhando da mesma visão crítica frente à padronização de procedimentos musicais na produção de canções ligadas ao samba, Tom Zé por sua vez coloca em questão justamente esses padrões que se formavam no mercado, adotando o gênero como fonte criativa para produzir o LP Estudando o samba, lançado pela gravadora Continental em I976. O título em si sintetiza sua unidade temática e a característica principal do disco: a proposta de analisar, decompor e recompor estruturas rítmicas, estilemas melódicos e temáticos, timbres instrumentais e formas tradicionais de interpretação do samba ${ }^{29}$. Em cada faixa do disco Tom Zé explorou os limites do gênero, experimentando novas possibilidades formais em seus diversos parâmetros: letras, linhas de condução rítmica, desenho melódico, instrumentação, métrica, tipo de arranjo, uso de ruídos, uso de dicções incomuns, emprego de ostinatos etc.

Nesse sentido, a postura do compositor iraraense na concepção artística do disco parece apresentar semelhanças com a própria concepção de experimentalismo de Boguslaw Schäffer, que a define como uma "atitude com que o compositor se debruça sobre o mundo dos sons para estudá-lo e abrir-lhe possibilidades até então ignoradas" ${ }^{30}$. Ao invés de aceitar e reproduzir o senso comum daquilo que era reconhecido como as características musicais do samba, Tom Zé se coloca em dúvida sobre esse conhecimento comum e procede a um estudo experimental, trabalhando empiricamente o gênero em seus parâmetros internos. Realiza assim, de certo modo, uma pesquisa experimental em sentido científico, decompondo alguns elementos estruturais do samba e reorganizando-os de maneira a gerar novos materiais na música popular.

O design da capa do disco, elaborado por Walmir Teixeira, também se vincula diretamente com a concepção artística experimental concebida:

29 VARGAS, Herom. As inovações de Tom Zé na linguagem da canção popular dos anos 1970. Galáxia: Revista do Programa de Pós-Graduação em Comunicação e Semiótica da PUC-SP, n. 24, 2012, p. 279-291.

30 Apud ECO, Umberto. A definição da arte. Rio de Janeiro: Elfos; Lisboa: Edições 70, 1968, p. 227. 


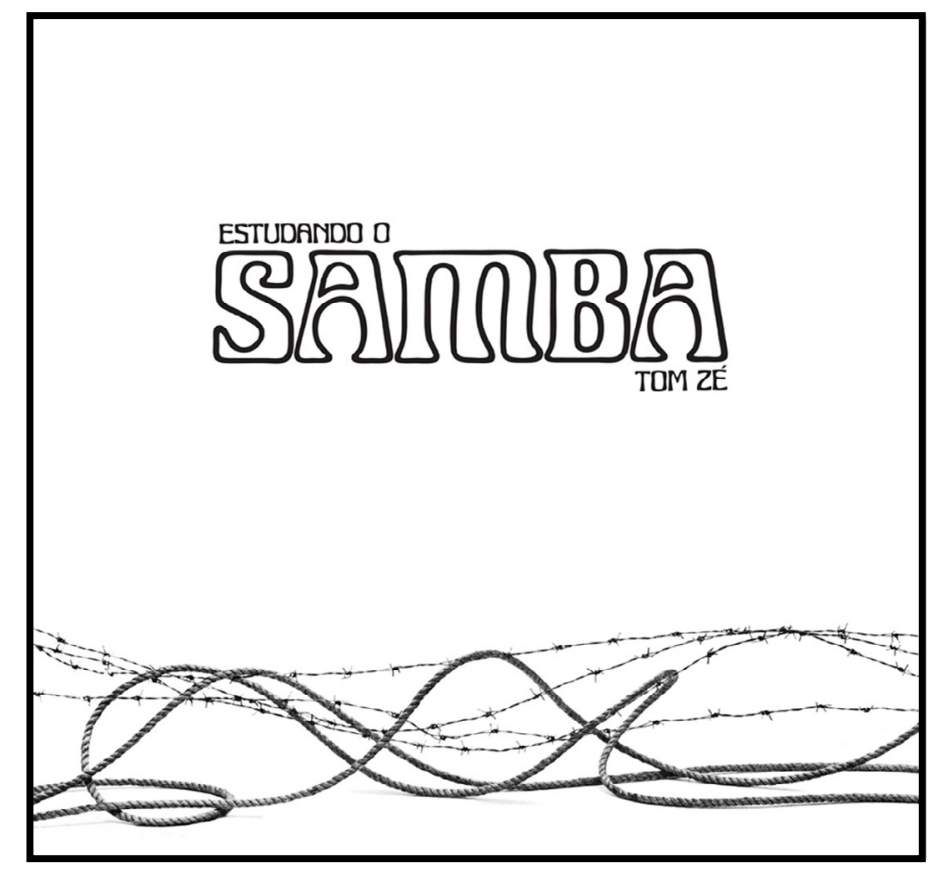

Figura 2 - Capa do LP Estudando o samba

Em uma figuração no mínimo inusitada, Walmir Teixeira utiliza na parte inferior da capa a figura de um arame farpado entrelaçado com outro cabo, que supostamente seria de um instrumento elétrico (por exemplo, guitarra ou baixo). Com essa composição associa o título do LP, e por consequência o gênero samba também, com as representações da figura do arame farpado, fio metálico entrelaçado com pontas penetrantes geralmente empregado para defender uma propriedade. A ligação simbólica entre esses signos pode tanto remeter ao contexto repressor da ditadura militar, como também pode fazer alusão a uma crítica ao gênero, que simbolicamente estaria sendo aprisionado por empresários e grandes gravadoras e deteriorado pelos mecanismos da indústria cultural ${ }^{31}$; ou mesmo como defesa do próprio Tom Zé e sua obra frente à censura política e à padronização. Como Lima aponta ${ }^{32}$, o cabo de instrumento pode fazer alusão à possibilidade de transmissão dos sons por meio dos fios, driblando as barreiras estéticas impostas pela censura.

A princípio o disco foi bem recebido por alguns jornalistas e críticos simpatizantes do trabalho de Tom Zé, que o elogiavam pela sua inventividade e criatividade singular contraposta a certa redundância identificada na produção de sambas do período. Vejamos a seguir trechos da resenha do crítico Tárik de Souza:

3I LIMA, Márcio Soares Beltrão de. O design entre o audivel e o visivel de Tom Zé. Dissertação (Mestrado em

Design). Universidade Anhembi Morumbi, 20I0, p. I46.

32 Ibidem. 
Aos oito anos de uma carreira irregular, iniciada ao lado de seus colegas de Tropicalismo, Gilberto Gil e Caetano Veloso, Tom Zé acumulou sucessos modestos ("São São Paulo", “Jeitinho Dela”, "Silêncio de Nós Dois”, “Se o Caso É Chorar”) e silenciosos fracassos. Por fim, misturando um e outro extremo de habilidades, parece ter chegado ao ambicionado ponto de equilíbrio em Estudando o Samba. Ao mesmo tempo, move-se agilmente pelos requebros do ritmo da moda e desmonta o velho gênero, faixa a faixa, em seus mais robustos lugares-comuns. Enfim, tanto é invenção quanto perfeitamente vendável. [...] Mas a impressão sonora do LP é mesmo de uma oficina de montagem: rufares inesperados varrem a plácida "Felicidade", de Antônio Carlos Jobim, enquanto "Toc", faixa apenas instrumental, tem uma colagem bem costurada, com solos de máquina de escrever e rádio de pilha ${ }^{33}$.

Podemos perceber que, na visão de Souza, Tom Zé teria alcançado no disco um ponto de equilíbrio entre inventividade e viabilidade comercial, dosando os extremos de suas habilidades. Ao destacar os experimentalismos praticados de maneira positiva e, além disso, sustentar que o LP é inventivo e ao mesmo tempo "vendável", o jornalista demonstra que, para ele, a presença de experimentalismos nas faixas não interfere em seu potencial de vendas. Além disso, destaca o caráter de estudo experimental do samba do projeto estético do disco, associando sua sonoridade a uma oficina de montagem.

Em outra linha argumentativa, Gilberto Vasconcellos também tece comentários positivos em um dos seus ensaios, destacando a importância do LP dentro do cenário do samba:

[...] Mas isso são filigranas em Estudando o Samba. Sua importância reside no todo, na imagem de conjunto que nos fica depois de ouvi-lo. O lançamento deste disco encerra um significado crítico e providencial. Independente da intenção ou consciência de seu autor, ele acaba por trazer à tona a questão do destino do samba, isto é, ele instiga a reflexão sobre a função cultural que desempenha o samba no atual momento da MPB. Isso não está, é claro, escancarado no seu disco. Mas[,] ao acabar de ouvi-lo, subitamente vem o desejo de comparar o tratamento que lhe dá Tom Zé com a redundância adoidada do samba praticado hoje em dia $^{34}$.

Para o sociólogo, o lançamento do LP incitava a reflexão sobre o papel que o samba estava desempenhando no período, evidenciando sua redundância através dos procedimentos criativos praticados por Tom Zé. Nas páginas seguintes do ensaio, o autor desenvolve seu argumento, sustentando que a grande repercussão comercial e popularização do segmento do sambão-joia representava o avanço da padronização, da pobreza artística, da despolitização da esfera cultural, e que não contribuía senão para "reforçar os valores da cultura oficial" 35 . Ainda adiante, afirma que o LP Estudando o samba e a produção de algumas canções experimentais se distinguiam

33 SOUZA, Tárik de. Ui! Hein?. Veja, n. 392, Io de março, I976, p. 90.

34 VASCONCELLOS, Gilberto, op. cit., p. 77.

35 Ibidem, p. 79. 
daquele segmento pelo seu significado crítico, pela criatividade, originalidade, por fugirem da banalidade e incitarem reflexão nos ouvintes, em vez de conformismo ${ }^{36}$.

Apesar de ser um disco centrado em um gênero que estava em grande popularidade e de ter conquistado elogios da crítica especializada, o LP Estudando o samba acabou não alcançando uma cifra significante de vendas no período. Seja pela suposta incompreensão frente ao grande público, seja pela sua incompatibilidade frente às tendências do mercado no período, o disco terminou não atraindo muita visibilidade, o que contribuiu para que a carreira de Tom Zé continuasse com dificuldades e baixas perspectivas.

Como pudemos perceber, diante de um cenário de grande popularização do samba e de sua crescente repercussão comercial, alguns críticos, jornalistas e músicos analisaram criticamente parte da produção de canções ligadas ao gênero. A partir de referenciais por vezes políticos, tradicionalistas ou mesmo adornianos, desqualificavam artistas como Antonio Carlos \& Jocafi, Luiz Ayrão, Benito di Paula, Gilson de Souza pela submissão aos imperativos mercadológicos da indústria cultural, condenando suas canções por estigmas como redundância, padronização, massificação, perda de suas origens comunitárias etc. Se na ótica de Vasconcellos o sucesso gerado por esse tipo de samba representava a falência daquele projeto de samba politizado de orientação nacional-popular da década de I960, em contrapartida, a produção de Tom Zé e a de outros artistas "malditos" escapavam à banalidade, expressando criticamente as contradições e as "adversidades repressivas do mundo real" 37 .

Considerando que, segundo Ortiz, "a implantação de uma indústria cultural modifica o padrão de relacionamento com a cultura, uma vez que definitivamente ela passa a ser concebida como um investimento comercial" ${ }^{8}$, e que ao longo da década de 1970 o valor de mercadoria dos produtos orientava cada vez mais as ações de produtores e também de alguns artistas em suas ações, ao produzir Estudando $o$ samba, Tom Zé parece ter se orientado em um sentido um pouco distinto. No momento em que dedicava um disco inteiro para um estilo musical em alta no mercado, ao mesmo tempo praticando métodos experimentais de criação artística e desconstruindo o gênero em seus diferentes matizes, o compositor baiano se valia do próprio veículo (o samba e seu sucesso no mercado) para lhe tecer uma crítica. Desse modo, de maneira semelhante à que Favaretto ${ }^{39}$ aponta em relação aos tropicalistas, Tom Zé parece assumir em sua carreira um compromisso com a ambiguidade existente entre mercado e crítica, na qual a crítica do capitalismo/da mercadoria acaba tornando-se mais um produto pelo seu potencial de vendas. Com o intuito de ganhar visibilidade e se legitimar no campo artístico, Tom Zé escolhe justamente o samba e suas peculiaridades literomusicais para colocá-las em questão, realizando musicalmente uma crítica das formas padronizadas do gênero e produzindo um produto no processo, o LP Estudando o samba, produto este que apresentou pouca eficiência em seu potencial atrativo de consumidores naquele período, apesar das suas qualidades em inventividade e inovação formal.

36 Ibidem, p. 77-82.

37 Ibidem, p. 80.

38 ORTIZ, Renato. A moderna tradição brasileira. São Paulo: Brasiliense, I994, p. I44.

39 FAVARETTO, Celso. Tropicália alegoria, alegria. São Paulo: Ateliê Editorial, I996, p. I39. 


\title{
AlgunS ESTUdOS EXPERIMENTAIS DE TOM ZÉ SObRE O SAMBA
}

Uma peculiaridade desse disco em relação aos de outros artistas e aos do próprio compositor iraraense é que cada faixa apresenta títulos exíguos ("Mã”, “Tô", “Ui!”, "Só”, “Se”, “Hein?”, “Dói”, “Mãe” etc.). Essa característica indica uma continuidade na carreira de Tom Zé da incorporação de elementos da poesia concreta, como a sintaxe não discursiva, a exploração da sílaba, a verbivocovisualidade e a concisão vocabular ${ }^{40}$, procedimento esse já explorado no disco anterior, Todos os olhos (I973). Porém, se essa incorporação de processos criativos concretistas se apresentou evidente em apenas alguns momentos desse disco, em Estudando o samba Tom Zé parece ampliar o emprego desse paradigma não apenas no título das faixas, mas também nas letras de grande parte das músicas, como veremos nas análises a seguir. Vale lembrar também que o coro nos arranjos das músicas, seja ele responsorial ou não, está presente desde o primeiro disco de Tom Zé e constitui um dos elementos da singularidade do seu projeto estético. Também nesse disco ele está presente na grande maioria das faixas com uma função planejada no arranjo, algo que destaca a relevância do papel desempenhado por esse recurso para o compositor baiano.

Iniciando o segundo lado do LP, a canção "Dói” é de autoria de Tom Zé e também apresenta processos criativos concretistas. Em seguida a transcrição de sua letra:

\author{
Dór \\ Maltratei, \\ sim, maltratei demais \\ e machuquei, \\ quei, quei, \\ quei, quei, \\ meu coração que bate \\ que bate calado \\ que bate calado \\ que bate, bate \\ e dói, dói, dói. \\ que bate e dói, \\ dói. \\ (Coro) Dói, amor \\ dói com d \\ ô dói e dói \\ amor ô \\ dói e dói.
}

40 BOSI, Alfredo. História concisa da literatura brasileira. São Paulo: Cultrix, 2006. 
Enquanto a interpretação de Tom Zé e o conteúdo da canção se alinham à poética emocional de sambas-canções, tratando da temática da "dor de cotovelo", a forma pela qual é estruturado nos versos destoa drasticamente das formas mais usuais de composição das letras desse subgênero. Além de apresentar frases bastante simples, com um vocabulário reduzido, nota-se também a exploração das sílabas, que são repetidas frequentemente do início ao final da canção, características essas recorrentes na poesia concreta. No plano musical, o arranjo de José Briamonte também escapa de procedimentos mais usuais do repertório de sambas, uma vez que utiliza coro sem uníssonos em alguns momentos, ou seja, empregando texturas polifônicas com abertura de vozes e até mesmo cânones imitativos no minuto final da faixa, procedimentos mais usualmente empregados na música erudita e extremamente incomuns no repertório de sambas. Especificamente no que se refere ao cânone, nota-se aí um ponto de tensão entre a tradição oral, que perpassa as práticas do samba desde suas origens, e a tradição escrita de corais contrapontísticos da música erudita. Apesar de estarem sobrepostas na mesma seção da música, as duas práticas acabam não criando uma relação orgânica entre si e assim se reafirmam suas diferenças. Enquanto o contorno melódico apresenta uma sonoridade que remete a melodias folclóricas, o cânone imitativo empregado no coro distancia a escuta desse tipo de "tradição" e de estruturas musicais mais amplamente empregadas em sambas e, por fim, acaba tensionando certos padrões de linguagem do gênero.

$\mathrm{D}$

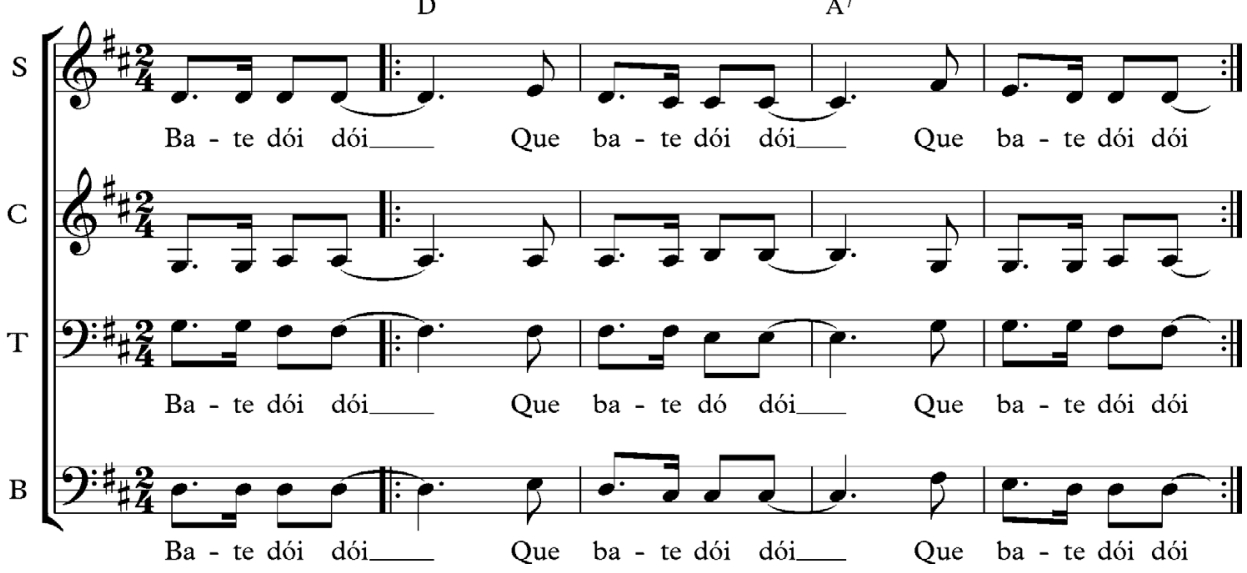

Figura 3 - Transcrição aproximada da abertura de vozes do coro nos refrães de "Dói” 


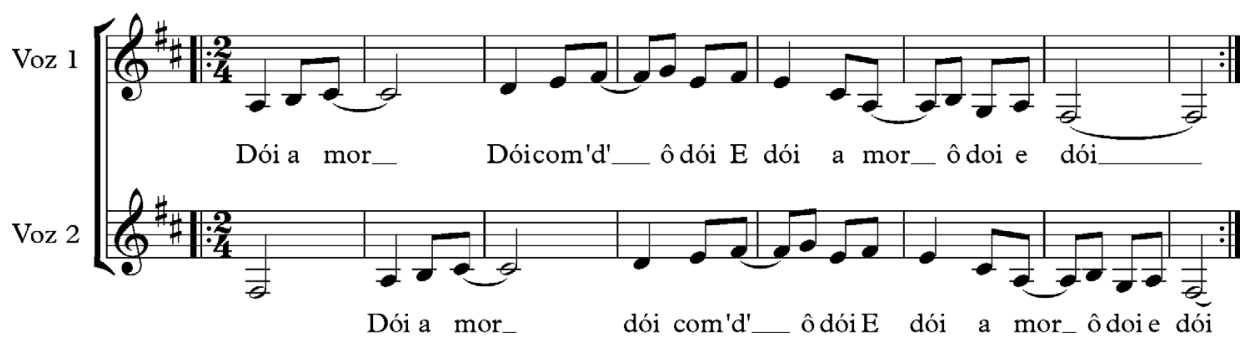

Figura 4-Transcrição das vozes do cânone imitativo no minuto final de "Dói”

A faixa seguinte do disco, "Mãe (Mãe solteira)" foi composta em parceria de Tom Zé com Elton Medeiros e, assim como "Só", aborda também em sua letra um tema recorrente no samba, a solidão. Segue abaixo sua transcrição:

\section{Mãe (Mãe solteira)}

Cada passo, cada mágoa

Cada lágrima somada

Cada ponto do tricô

Seu silêncio de aranha

Vomitando paciência

Pra tecer o seu destino

Cada beijo irresponsável

Cada marca do ciúme

Cada noite de perdão

O futuro na esquina

E a clareza repentina

De estar na solidão

(Coro) Dorme, dorme

Meu pecado

Minha culpa

Minha salvação

Os vizinhos e parentes

A sociedade atenta

E a moral com suas lentes

Com desesperada calma

Sua dor calada e muda

Cada ânsia foi juntando

Preparando a armadilha

Teias, linhas e agulhas

Tudo contra a solidão 
Pra poder trazer um filho

Cuja mãe são seus pavores

E o pai sua coragem

Nos primeiros acordes da canção, a levada característica de João Gilberto executada já marca o dialogismo com o gênero da bossa nova. A incursão nesse estilo se confirma nos compassos seguintes com a entrada de cordas, flauta, violoncelo, fagote executando notas longas que se movem por graus conjuntos, ressaltando as tensões passionais ${ }^{4 \mathrm{I}}$ e construindo uma textura típica de arranjos do gênero. $\mathrm{O}$ caráter camerístico da interpretação dos músicos e de Tom Zé também se alinha ao tipo de interpretação bossa-novista e também reforça a expressividade do sentimento de solidão presente na letra. Entretanto, se de um lado o arranjo e a forma de interpretação se alinham aos estilemas da bossa nova, por outro lado sua temática diverge substancialmente do projeto utópico e da recorrente promessa de felicidade bossa-novista ${ }^{42}$. Ao invés do lirismo de figuras como o "amor, o sorriso e a flor", despontam em "Mãe" imagens sombrias de mágoa, dor, lágrima e solidão ao retratar o cotidiano de uma mãe solteira. Versos que fazem uma associação metafórica com a aranha, tecendo o seu destino, preparando armadilhas com teias, linhas e agulhas, também escapam do tipo de figurativa poética usual da bossa nova. Além disso, a entrada da bateria e da percussão (surdo) na seção rítmica dos refrães descaracteriza o tipo de acompanhamento bossa-novista praticado no início da música, conferindo à condução rítmica um caráter mais próximo de samba. Desse modo, a canção se alinha ao projeto estético do disco, uma vez que decompõe estilemas temáticos da bossa nova (gênero derivado do samba), explorando novas possibilidades formais ao abordar poeticamente as fraquezas e insuficiências do seu personagem.

\section{CONSIDERAÇõES FINAIS}

Com base em matérias publicadas em periódicos, pudemos perceber que, após a ousadia criativa e a repercussão desfavorável causada pelo disco Todos os olhos (I973), Tom Zé se distanciou da cena artística oficial e passou a atuar em espaços alternativos de menor visibilidade. Devido à postura contrária a certos padrões culturais dominantes e às suas práticas criativas, consideradas ousadas, transgressoras e herméticas pela crítica especializada, acabou recebendo o rótulo de cancionista "marginal" ou "maldito", junto de outros artistas, como Jards Macalé, Jorge Mautner, Walter Franco, Marcus Vinicius, entre outros. Nesse sentido, tentamos problematizar as relações entre as opções estéticas de Tom Zé, sua forma de atuação no mercado do período e o segmento conhecido como cultura marginal. Ao analisarmos essas relações, pudemos perceber que, apesar de ter divergido nas temáticas abordadas em suas canções, poucas vezes tratando de violência urbana em suas músicas, Tom Zé compartilhou do mesmo tipo de estratégia de atuação e postura underground,

4I TATIT, Luiz. O cancionista: composição de canções no Brasil. São Paulo: Edusp, I995.

42 MAMMİ, Lorenzo. João Gilberto e o projeto utópico da bossa nova. Novos Estudos CEBRAP, n. 34, I992, p. 63-70. 
antagônica aos padrões culturais, estéticos e políticos propagados pelo regime militar. Assim, ao invés de aproximar o seu trabalho a certos modelos compatíveis com o gosto popular, Tom Zé optou por se manter fiel às suas convicções estéticas e desenvolveu ainda mais seu projeto estético experimental nos anos seguintes da década de I970, justamente em um momento pouco oportuno para inovações musicais no mercado.

Com base nos seus conhecimentos sobre os procedimentos de vanguarda da música erudita, obtidos na sua formação acadêmica na UFBA, o compositor baiano elaborou o projeto da "música operária", empregando ferramentas, máquinas de oficinas e sons oriundos da execução de fitas magnéticas para realizar suas performances. Desse modo, adaptava um procedimento típico dos concretistas franceses para o universo da música popular.

Ao cotejarmos algumas análises acadêmicas com canções de alguns compositores, discursos proferidos em periódicos sobre o gênero samba e estatísticas dos discos mais vendidos, observamos que ao longo da década de I970 o segmento passou por uma fase de revitalização e ascensão de popularidade no mercado. Diante desse fenômeno, diversos jornalistas, críticos e sambistas apresentaram uma visão crítica comum sobre a popularização do samba em suas análises, destacando, nas transformações correntes do gênero, certo processo de padronização, descaracterização de suas práticas originais, perda de originalidade criativa, massificação, fenômeno que associaram ao avanço da racionalidade mercadológica e às estratégias de marketing. Compartilhando da mesma visão crítica, Tom Zé por sua vez coloca em questão justamente esses padrões que se formavam no mercado, adotando o gênero como fonte criativa para produzir o LP Estudando o samba. Através da apreciação do disco, pudemos perceber que o seu projeto estético se baseou na proposta experimental de analisar, decompor e recompor estruturas rítmicas, estilemas melódicos e temáticos, timbres instrumentais e formas tradicionais de interpretação do samba. Nas análises das canções "Dói” e "Mãe" identificamos algumas maneiras pelas quais Tom Zé desconstruiu certos padrões de interpretação do gênero, as quais consistiram no uso de cânone imitativo e figuras temáticas inusitadas. Observamos também que, em outros fonogramas do disco, o artista adaptou procedimentos musicais da vanguarda da música erudita ao campo de música popular, empregando polimetrias e clusters, e tensionando dessa maneira certos padrões de linguagem e conduta consolidados no mercado. 
GUILHERME ARAUJO FREIRE é doutorando em Música pelo Programa de Pós-graduação da Universidade Estadual de Campinas (Unicamp). Participa de reuniões semanais do grupo de pesquisa "Música popular: história, produção e linguagem" (CNPq) desde 20Io, sob coordenação dos profs. drs. Rafael dos Santos e José Roberto Zan.

E-mail: guilhermefreirea@gmail.com

\section{REFERÊNCIAS BIBLIOGRÁFICAS}

ARROJO, Maria José. Tom Zé, um quarentão inocente. Folha de S. Paulo, Ilustrada, 3 dez. I977, p. I.

AUTRAN, Margarida. Samba, artigo de consumo nacional. In: NOVAES, Adauto. Anos 70: ainda sob a tempestade. Rio de Janeiro: Aeroplano/Editora Senac Rio, 2005, p. 7I-78.

BOSI, Alfredo. História concisa da literatura brasileira. São Paulo: Cultrix, 2006.

CABRAL, Sérgio. A subida do samba. Veja, n. 586, p. 3-6. Entrevista concedida a Elizabeth Carvalho.

COELHO, Frederico. Eu, brasileiro, confesso minha culpa e meu pecado: cultura marginal no Brasil das décadas de I960 e I970. Rio de Janeiro: Civilização Brasileira, 2010.

DUCLOS, Nei. Contradições de um artista em construção. Folha de S. Paulo, Ilustrada, I9 mai. I978, p. 2. ECO, Umberto. A definição da arte. Rio de Janeiro: Elfos; Lisboa: Edições 70, I968.

FAVARETTO, Celso. Tropicália alegoria, alegria. São Paulo: Ateliê Editorial, I996.

GRIFFITHS, Paul. A música moderna: uma história concisa e ilustrada de Debussy a Boulez. Rio de Janeiro: Jorge Zahar, I998.

LIMA, Márcio Soares Beltrão de. O design entre o audivel e o visível de Tom Zé. Dissertação (Mestrado em Design). Universidade Anhembi Morumbi, 2010.

MACHADO, Adelcio Camilo. Quem te viu, quem te vê: o samba pede passagem para os anos I970. Dissertação (Mestrado em Música). Instituto de Artes, Universidade Estadual de Campinas, $20 I I$.

MAMMİ, Lorenzo. João Gilberto e o projeto utópico da bossa nova. Novos Estudos CEBRAP, n. 34, I992, p. 63-70.

NAPOLITANO, Marcos. Seguindo a canção: engajamento político e indústria cultural na MPB (I959-I969).

São Paulo: Annablume/Fapesp, 2001.

ORTIZ, Renato. A moderna tradição brasileira. São Paulo: Brasiliense, I994.

PAIANO, Enor. O berimbau e o som universal: lutas culturais e indústria fonográfica nos anos 60. Disserta-

ção (Mestrado em Comunicação). Escola de Comunicações e Artes, Universidade de São Paulo, I994. SCARASSATTI, Marco Antônio Farias. Walter Smetak, o alquimista dos sons. São Paulo: Perspectiva, 2008. SOARES, Dirceu. Tom Zé, do Brás ao Jardim América. Folha de S. Paulo, Ilustrada, 2I mai. I977, p. 2. SOUZA, Tárik de. País do samba. Veja, n. 37I, I975, p. I2I-I22. . Ui! Hein?. Veja, n. 392, 1976, p. 90.

TATIT, Luiz. O cancionista: composição de canções no Brasil. São Paulo: Edusp, I995. . O século da canção. São Paulo: Ateliê Editorial, 2004. 
TOM ZÉ “escapando da morte”. Folha de S. Paulo, Ilustrada, 6 mar. I973, p. 5.

TOM ZÉ ligado às origens. O Estado de S. Paulo, Geral, 20 mai. I978, p. I2.

TOM ZÉ ou Quem irá colocar uma dinamite na cabeça do século?. 2000. Dir. Carla Gallo. DVD.

VARGAS, Herom. As inovações de Tom Zé na linguagem da canção popular dos anos I970. Galáxia: Revista do Programa de Pós-Graduação em Comunicação e Semiótica da PUC-SP, n. 24, 20I2, p. 279-29I.

VASCONCELLOS, Gilberto. Música popular: de olho na fresta. Rio de Janeiro: Edições do Graal, I977.

VICENTE, Eduardo. Música e disco no Brasil: a trajetória da indústria nas décadas de 80 e 90 . Tese (Doutorado em Comunicações). Escola de Comunicações e Artes, Universidade de São Paulo, 200I.

. Segmentação e consumo: a produção fonográfica brasileira I965/I999. ArtCultura, v. Io, n. I6, 2008, p. 99-II7

ZAN, José Roberto. Jards Macalé: desafinando coros em tempos sombrios. Revista USP, n. 87, 20Io, p. I56-I7I.

ZÉ, Tom. Tropicalista lenta luta. São Paulo: Publifolha, 2003. 